\title{
Giant Lactating Adenoma - Size of a Shot Put Ball
}

\author{
Sherif Monib, Mohamed Elkorety \\ West Hertfordshire Hospitals NHS Trust, Hertfordshire, UK
}

Doi: 10.12890/2020_001579 - European Journal of Case Reports in Internal Medicine - @ EFIM 2020

Received: $13 / 02 / 2020$

Accepted: $18 / 02 / 2020$

Published: $18 / 03 / 2020$

How to cite this article: Monib S, Elkorety M. Giant lactating adenoma - size of shot put ball. EJCRIM 2020;7: doi:10.12890/2020_001579.

Conflicts of Interests: The Authors declare that there are no competing interests.

This article is licensed under a Commons Attribution Non-Commercial 4.0 License

\section{ABSTRACT}

Lactating adenomas are benign breast tumours which normally present in the peripartum period. Aetiology, pathogenesis, best diagnostic modality and management are not yet clear in the literature. We present a case of a 32-year-old pregnant patient who was re-referred to us with a progressively increasing left breast lesion, pre-existing prior to pregnancy, which was found to be a huge lactating adenoma.

\section{LEARNING POINTS}

- Pregnant and lactating women should stay breast aware and perform monthly breast self-examinations to detect any abnormalities at an early stage.

- In the absence of specific ultrasound features to identify lactating adenoma, triple assessment, including core biopsy, is the mainstay of diagnosis.

- Lactating adenomas, especially those potentially related to a pre-existing breast lesion or large in size, should be reported in order to develop evidence-based management guidelines.

\section{KEYWORDS}

Benign breast disease, lactation, lactating adenoma, lactational adenoma

\section{INTRODUCTION}

Lactating adenomas are benign breast tumours which tend to present during pregnancy or shortly afterwards as palpable, well-circumscribed lobulated masses varying in size ${ }^{[1]}$. In some cases they might cause clinical concern due to their progressive growth;hence, triple assessment is mandatory even whenthe clinical impression is of lactating adenoma.Our case report is unique as it concerns alactating adenoma that developed in relation to a pre-existing small breast lesion, which progressively increased to the giant size of a shot put ball.

\section{CASE DESCRIPTION}

We present a case of a primiparous 32-year-old female who was re-referred to our breast unit with a progressively increasing left breast lump.The patient was 20 weeks pregnant at presentation andnoticed that a previously known benign left breast lump progressively increased in size during pregnancy.Past medical history included investigation of a left breast lump 2 years prior to presentation. A breast ultrasound scan at that time showed a $13 \mathrm{~mm}$ mass (Fig. 1, left), while histology revealed fibroadenomatoid changes (B2).

General examination was unremarkable, while breast examination revealed a large ovoid, firm mass in the lower inner quadrant of the left breast, with no other palpable suspicious lumps or axillary or supraclavicular lymph nodes. A left breast ultrasound scan showed the previously known lump had increased in size to more than $93 \mathrm{~mm}$ (Fig. 1, right).

Due to the progressive increase in size, a breast magnetic resonance imaging (MRI) scan was recommended, which confirmed a $130 \mathrm{~mm}$ mass in the lower inner quadrant of the left breast, displacing the surrounding breast tissue with no evidence of infiltration of the skin or any surrounding tissue (Fig. 2).Based on MRI findings, an ultrasound-guided biopsy was performed, which showed benign features compatible with lactating adenoma (B2). Due to the unusual presentation, our multidisciplinary team recommended a post-partum excision of themass. 

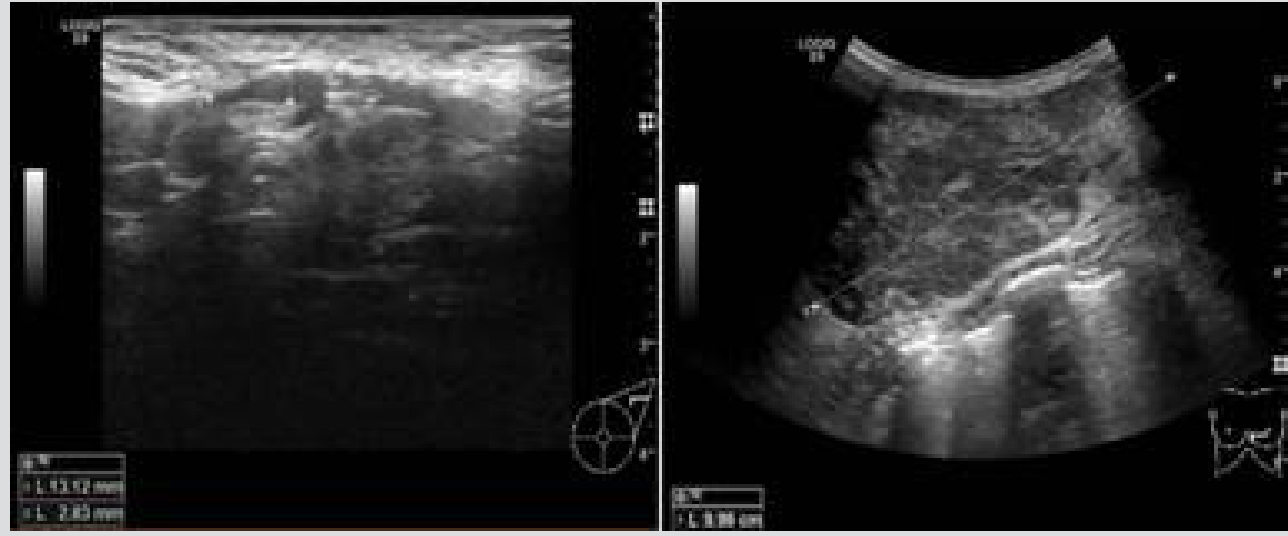

Figure 1. Left breast ultrasound scan showing $a$ $13 \mathrm{~mm}$ lesion at initial presentation (left) and a $93 \mathrm{~mm}$ lesion during pregnancy (right)

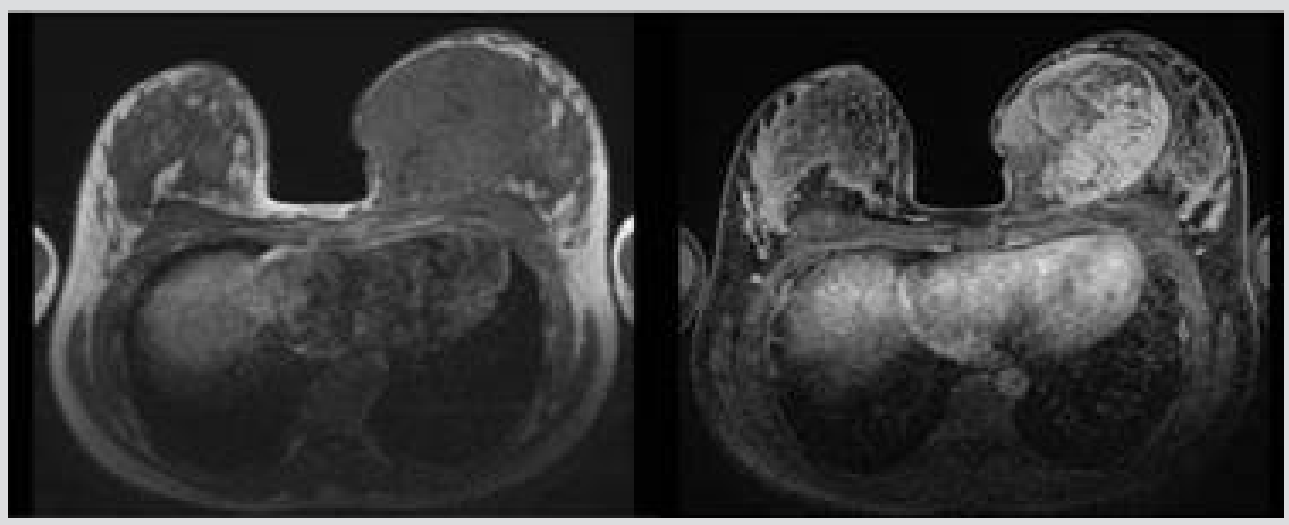

Figure 2. Breast MRI scan showing a $130 \mathrm{~mm}$ lactating adenoma (left T1, right T2)

\section{DISCUSSION}

There has been no consensus among pathologists on whether lactating adenoma is considered a specific condition which originates during pregnancy or due to changes induced in pregnancy over pre-existing fibroadenomas or tubular adenomas ${ }^{[2]}$. Breast lesions presenting during pregnancy or shortly afterwards are found to be benign in $80 \%$ of patients but determining the nature of the lump as well as its pathogenesis is still in question. Vashi et al. suggested the possibility of a hormonal influence on pre-existing benign breast lesions allowing them to grow during pregnancy ${ }^{[3]}$.

Breast-related pregnancy-induced changes, including stromal involution, glandular proliferation and ductal dilatation, make the clinical and radiological assessment somewhat challenging when differentiating lactating adenomas from other benign breast lesions encountered during pregnancy such as fibroadenomas ${ }^{[4]}$.

Due to the radiation risk as well as increased breast density duringpregnancy, breast ultrasound scan is considered the first-line diagnostic modality for investigating breast lesions during pregnancy and lactation ${ }^{[5]}$. Despite the fact that mammograms are not normally carried out during pregnancy, Parnes et al. described mammographic findings of lactating adenoma as a well-defined lobulated mass with fat density or fluid-fat level[ ${ }^{[6]}$.

Histologically, lactating adenomas appear as well circumscribed, lobulated, solitary or multiple, grey in colour with areas of necrosis;microscopically, they are seen as cuboidal cells with actively secreting, closely packed glands ${ }^{[7]}$. Barco Nebreda et al. recommend surgical excision for lactating adenomas which do not resolve spontaneously ${ }^{[8]}$.

\section{CONCLUSION}

Lactating adenoma is an entity of benign breast disease which is unfortunately lacking clear aetiology and management guidelines. We therefore recommend that cases with lactating adenomas, especially those potentially related to a pre-existing breast lesion or large in size, should be reported in order to develop evidence-based management guidelines.In the absence of specific ultrasound features to identify lactating adenoma, triple assessment, including core biopsy, is the mainstay of diagnosis. 


\section{REFERENCES}

1. Faguy K. Breast disorders in pregnant and lactating women. Radiol Technol 2015;86(4):419m-438m.

2. Slavin JL, Billson VR, Ostor AG.Nodular breast lesions during pregnancy and lactation. Histopathology 1993;22(5):481-485

3. Vashi R, Hooley R, Butler R, Geisel J, Philpotts L. Breast imaging of the pregnant and lactating patient: physiologic changes and common benign entities. AJRAm J Roentgenol 2013;200(2):329-336.

4. Hamza AA, Idris SA. Lactating adenoma of the breast a diagnostic difficulty in pregnancy and rewarding natural history during lactation: a case report and review of literature. Medicine Journal 2014;1(1):13-16.

5. Langer A, Mohallem M,Berment H, Ferreira F, Gog A, Khalifa D,et al.Breast lumps in pregnant women. Diagn Interv Imaging 2015;96(10):1077-1087.

6. Parnes A, Akalin A, Quinlan RM, Vijayaraghavan GR. AIRP best cases in radiologic-pathologic correlation: lactating adenoma. Radiographics 2013;33:455-459.

7. Hind Warzecha, M.D. Pathology Outlines.com website. http://www.pathologyoutlines.com/topic/breastlactatingadenoma.html[accessed 03/03/2020].

8. Barco Nebreda I, Vidal MC, Fraile M, Canales L, González C, Giménez N, et al.Lactating adenoma of the breast. J Hum Lact 2016;32(3):559-562. 